\title{
$A$ «TRANSGRESSÃO DO UNIVERSAL»: O INTELECTUAL E O PODER EM MICHEL FOUCAULT
}

\author{
André Constantino Yazbek* \\ acyzk@hotmail.com
}

\begin{abstract}
RESUMO A partir da correlação, postulada pelo pensamento de Michel Foucault, entre o exercício do poder e a manifestação da verdade, o presente artigo pretende retraçar as exigências políticas de sua filosofia, relacionandoas com a figura de um tipo intelectual que tem por função não mais a defesa da universalidade, mas sim sua transgressão política e teórica - quer dizer: "política" porque "teórica”.
\end{abstract}

Palavras-chave poder, verdade, transgressão do universal, ética e genealogia.

ABSTRACT From the correlation, postulated by the thought of Michel Foucault, between the exercise of the power and manifestation of the truth, this paper aims to retrace the political demands of his philosophy, linking them to the figure of an intellectual type who has no more basis for the defense of universality, but its political and theoretical transgression - it means: "political" because "theoretical".

Keywords power, truth, transgression of the universal, ethics and genealogy.

* Professor Adjunto Doutor de Filosofia do Departamento de Ciências Humanas da Universidade Federal de Lavras. Artigo recebido em 28/9/2010 e aceito em 20/5/2011.

KRITERION, Belo Horizonte, $n^{\text {o }}$ 125, Jun./2012, p. 251-262. 
I.

"Acontece que as massas, no momento do fascismo, desejam que alguns exerçam o poder". ${ }^{1}$ Essas são as palavras de Michel Foucault em seu já célebre diálogo com Gilles Deleuze, publicado em 1972 na revista $L$ 'arc sob o título de Os intelectuais e o poder. Como se sabe, e segundo a periodização consagrada, estamos no momento da chamada genealogia foucaultiana, momento em que o pensamento foucaultiano dedica-se à análise das formas de exercício do poder. Trata-se, em uma palavra, de analisar o saber em termos de estratégias e táticas de poder, localizá-los como peça de relações de poder ou dispositivos políticos. No âmbito da genealogia foucaultiana, a própria "questão do direito, do julgamento, da justiça e da punição, não podem mais evitar seu desvio em direção ao arbítrio que as funda". ${ }^{2}$ Arbitrio, isto é: a prática genealógica implica em analisar o poder não mais em termos de direito, mas, ao contrário, em analisar os sistemas de direito em termos de poder.

Gostaria de partir deste arrazoado de ideias para localizar, nos anos derradeiros da produção intelectual de Michel Foucault, a "pequena démarche lateral" proposta pelo filósofo como procedimento - genealógico - de "mise en question" da necessidade de todo o poder, quer dizer, de sua aceitação de pleno direito. Trata-se das primeiras horas de um curso pronunciado por Foucault no Collège de France que terá por título Du gouvernement des vivants (1980):

Digamos, se quiserem, que se a démarche, se a grande démarche filosófica consiste em empregar uma dúvida metódica que coloca em suspenso qualquer certeza, a pequena démarche lateral e a contrapelo que thes proponho consiste, portanto, em tentar jogar sistematicamente não com a suspensão de todas as certezas, mas com a não necessidade de todo o poder, qualquer que seja ele. ${ }^{3}$

"A não necessidade de todo o poder, qualquer que seja ele": eis, de acordo com Foucault, a atitude propícia para acolher as consequências de uma inversão decisiva na forma de colocar a questão "filosófico-política" por excelência do pensamento ocidental. A pergunta que se deve fazer não é mais

1 FOUCAULT, Michel. "Os intelectuais e o poder : conversa entre Michel Foucault e Gilles Deleuza". In: MACHADO, Roberto (org.). Microfísica do poder. Organização, Introdução e Revisão Técnica de Roberto Machado. Rio de Janeiro: Graal, 2002, p. 77.

2 EWALD, François. "La philosophie comme acte". In: Le magazine litterárie. Dossier Michel Foucault: une étique de la vérité, n. 435, octubre, 2004, p. 30.

3 FOUCAULT, Michel. Du gouvernement des vivants: cours au collège de France, du 9 janvier au 26 mars 1980. Inédito. Disponível para consulta em áudio, sob notação: FCL - C 62 (1.1) / C62 (1.2) até FCL - C 62 (12.1) / C62 (12.2), arquivos do Institut Mémoire de L'Édition Contemporaine (IMEC), Caen, aula do dia 30 de janeiro de 1980, referência C62 (4.1). 
"haja vista o vínculo que me liga voluntariamente à verdade, o que se pode dizer do poder ?", mas sim, "haja vista minha vontade, decisão e esforços para me desligar do vínculo que me liga ao poder, o que resta, então, do sujeito do conhecimento e da verdade?" É nessa inversão de perspectivas que pretendo me concentrar. $\mathrm{O}$ curso $\mathrm{Du}$ gouvernement des vivants, consagrado às práticas cristãs de confissão ${ }^{5}$, inicia-se precisamente por uma análise de Édipo-Rei, de Sófocles, na qual Foucault procura assinalar três temas: 1) a relação entre a manifestação da verdade e o exercício do poder; 2) a importância e a necessidade, para o próprio exercício do poder, de uma manifestação da verdade que, de modo indispensável, toma a forma da subjetividade; 3) a manifestação da verdade sob a forma da subjetividade tendo por efeito algo que está bem além do conhecimento utilitário para o exercício do poder (não se trata, pura e simplesmente, de um "donner à connaître"). ${ }^{6}$ Daí a conclusão a ser retirada da análise foucaultiana a respeito de Édipo-Rei: "o poder, em geral, não saberia exercer-se se a verdade não é manifestada"?

Não se pretende refazer, aqui, o trajeto foucaultiano em sua análise do Édipo-Rei. Para os nossos propósitos, basta assinalar que Foucault toma a peça de Sófocles como um caso preciso e definido da relação entre exercício do poder e a manifestação da verdade. ${ }^{8} \mathrm{O}$ que está em jogo, nessa leitura efetuada em 1980, não difere muito daquilo que constituirá as linhas de força da leitura de Édipo-Rei em A verdade e as formas jurídicas (conjunto de cinco conferências pronunciadas na Pontifícia Universidade Católica do Rio de Janeiro no ano de 1973): a tragédia de Édipo será considerada por Foucault como "representativa e, de certa maneira, instauradora de um determinado tipo de relação entre o poder e o saber, entre o poder político e o conhecimento, de que nossa civilização ainda não se libertou". ${ }^{9}$ Que tipo de relação é essa?

$\mathrm{O}$ que aconteceu na origem da sociedade grega, na origem da idade grega do século $\mathrm{V}$, na origem de nossa civilização, foi o desmantelamento desta grande unidade

5 Grosso modo, trata-se de mostrar como se estabelece, em nossa cultura e a partir das feições que a prática da confissão cristã adquirirá nas comunidades monásticas dos primeiros séculos de nossa era, "le principe d'une véridiction de soi-même à travers l'herméneutique de la pensée". Cf. FRANÇOIS, Jean. "Aveu, vérité, justice et subjectivité. Autour d'un enseignement de Michel Foucault". In: Revue Interdisciplinaire d'Études Juridiques, n. 7, 1981. Disponível para consulta em texto datilografado, sob a notação: Compte rendu du cours "Mal faire, dire vrai. Fonctions de l'aveu" (Louvain, 1981), D 202, arquivos do Institut Mémoire de L'Édition Contemporaine (IMEC), Caen, p. 170.

6 FOUCAULT, Du gouvernement des vivants, op. cit., aula do dia 30 de janeiro de 1980, referência C62 (4.1).

7 Idem, ibidem.

8 Idem ibidem, aula do dia 16 de janeiro de 1980, referência C62 (2.1), arquivos do IMEC.

9 FOUCAULT, Michel. A verdade e as formas jurídicas. Trad. Roberto Cabral de Melo Machado e Eduardo Jardins Morais. Supervisão final do texto Lea Porto de Abreu Novaes et al. Rio de Janeiro: Editora NAU, 2003, p. 31. 
de um poder político que seria ao mesmo tempo um saber. /.../ quando a Grécia clássica aparece - Sófocles representa a data inicial, o ponto de eclosão -, o que deve desaparecer para que a sociedade exista é a união do poder e do saber. A partir deste momento o homem do poder será o homem da ignorância. Finalmente, o que aconteceu a Édipo foi que, por saber demais, nada sabia. A partir desse momento, Édipo vai funcionar como o homem do poder, cego, que não sabia e não sabia porque podia demais. /.../ O Ocidente vai ser dominado pelo grande mito de que a verdade nunca pertence ao poder político, de que o poder político é cego, de que o verdadeiro saber é o que se possui quando se está em contato com os deuses ou nos recordamos das coisas, quando olhamos o grande sol eterno ou abrimos os olhos para o que se passou. Com Platão se inicia um grande mito ocidental: o de que há antinomia entre saber e poder. Se há saber, é preciso que ele renuncie ao poder. Onde se encontra saber e ciência em sua verdade pura, não pode mais haver poder político. Este grande mito precisa ser liquidado. /.../ O poder político não está ausente do saber, ele é tramado com o saber. ${ }^{10}$

No nível de generalidade em que estamos, poder-se-ia ainda remeter as citações acima, tanto aquela de 1980 quanto essa de 1973, ao "Prefácio" que Foucault escreverá à edição americana de $O$ anti-Édipo, Capitalismo $e$ esquizofrenia (1977). Qualificando a obra de Deleuze e Guattari como uma "introdução à vida não-fascista" ("não somente o fascismo histórico de Hitler e Mussolini /.../, mas também o fascismo /.../ que nos faz gostar do poder, desejar essa coisa mesma que nos domina e nos explora"), Foucault se pergunta: "Como fazer para não se tornar fascista mesmo (e sobretudo) quando se acredita ser um militante revolucionário?"'1, para logo em seguida arrematar, "Não exijam da política que ela restabeleça os 'direitos' do indivíduo tal como a filosofia os definiu. O indivíduo é o produto do poder."12 E é sintomático, nesta medida, que em 1980 Foucault venha a classificar a sua própria démarche como uma "anarqueologia" - espécie de "jeu des mots", por meio da qual a arqueo-genealogia foucaultiana se irmana ao "anarquismo" contido na posição metodológica que Foucault pretende levar adiante em $D u$ gouvernement des vivants: a não necessidade do poder serviria de princípio de inteligibilidade do próprio saber. ${ }^{13}$ Eis um exemplo da maneira de proceder requerida por este posicionamento:

10 Idem, ibidem, p. 51.

11 FOUCAULT, Michel. "Préface". In: Dits et écrits II. 1976-1988. Paris: Quarto Gallimard, 2001, pp. 134-135 (grifo nosso).

12 Idem, ibidem, p. 135.

13 FOUCAULT, Du gouvernement des vivants, op. cit., aula do dia 30 de janeiro de 1980, referência C62 (4.1). Isso não significa, bem entendido, que Foucault tenha assumido uma posição redutível a uma espécie de anarquismo de tipo particular - donde o neologismo "anarchéologie". E é o próprio Foucault, definindo o anarquismo de maneira aproximada, quem se apressa em traçar a linha fronteiriça: enquanto a tese anarquista concebe o poder, em seu nascimento mesmo e de todo e qualquer modo que ele se apresente, como um mal per si, visando a uma sociedade na qual todas as relações de poder fossem anuladas, 
Antes, portanto, de tomar como medida da prisão e de sua reforma possível a própria delinquência ou o próprio homem, tratava-se de ver como esta prática do enclausuramento, esta prática da punição em nossa sociedade modificou, de uma parte, é claro, a prática real de inegalismos [inégalismes], mas também constituiu este duplo entre o sujeito de direito e o homem criminoso, sujeito de direito e "hommo criminaliste", no qual se extraviou, ou se extravia sempre, e em definitivo, nossa prática penal. ${ }^{14}$

Decerto, os três textos citados acima não saberiam desligar-se de um diagnóstico de época, devidamente explicitado no texto de 1977: se durante os anos de 1945 e 1965 ("falo da Europa"), havia "certa maneira correta de pensar, certo estilo de discurso, certa ética do intelectual” (era necessário "ser íntimo de Marx, não deixar os sonhos vagarem longe demais de Freud e tratar o sistema de signos - o significante - com grande respeito"), passados cinco anos de "júbilo e enigma", a equação já não era mais a mesma. O que se passou então não foi uma retomada do "projeto utópico dos anos 30" (agora, como queria Jean-Paul Sartre, na "escala da prática histórica"15), mas um "movimento em direção a lutas políticas que não se conformavam mais ao modelo prescrito pela tradição marxista". ${ }^{16}$ E se as lições de 1980 nos interessam aqui, é na medida em que elas parecem explicitar, no âmbito da "teoria", um aprendizado colhido na esfera da "prática efetiva"; elas são, naquilo que nos interessa, um valioso testemunho de uma compreensão, forjada na luta, da tarefa filosófica como sendo aquela de uma espécie de jornalismo radical: pensar o atual, e não mais o "eterno", explicitar o ponto a partir do qual se fala, e não mais partir de um pretenso ponto eqüidistante, universal, universalizante. ${ }^{17}$

Foucault, de sua parte, previne-nos que não se trata de afirmar que todo poder é "mau", mas apenas de partir do ponto de vista de que nenhum poder é aceitável de pleno direito, e de que, por outro lado, ele é, ao mesmo tempo, absolutamente e definitivamente inevitável. Assim, não se trata aqui de visar a um projeto de uma sociedade sem relações de poder - algo que a própria genealogia não permitiria -, mas de assumir a não-aceitação do poder (não no fim, mas já no início mesmo da démarche, como um "pressuposto") sob a forma de "mis en question" de todos os modos segundo os quais nós efetivamente tomamos por aceito o poder. Cf. Idem, ibidem.

14 Idem, ibidem.

15 Como se sabe, para o Sartre da Critique de la raison dialectique (1960) o marxismo é a "filosofia insuperável" do nosso tempo: "il est indépassable parce que les circonstances qui l'ont engendré ne sont pas encore dépassées." Cf. SARTRE, Jean-Paul. Critique de la raison dialectique (précédé de Question de méthode). Tome I: théorie des ensembles pratiques. Bibliothèque des Idées. Paris: Gallimard, 1960, p. 29.

16 FOUCAULT, "Préface", op. cit., p. 133.

17 "Je me considère comme un journaliste", dirá Foucault em 1973, "dans la mesure où ce qui m'intéresse, c'est l'actualité, ce qui se passe autour de nous, ce que nous sommes, ce qui arrive dans le monde. La philosophie, jusqu'à Nietzsche, avait pour raison d'être l'éternité. /.../ Avant, le philosophe connaissait le temps et l'éternité. Mais Nietzsche avait l'obsession de l'actualité. /.../ Si nous voulons être maîtres de notre futur, nous devons poser fondamentalement la question de l'aujourd'hui. C'est pourquoi, pour moi, la philosophie est une espèce de journalisme radical." FOUCAULT, Michel. "Le monde est un grand asile". In: Dits et écrits I. 1954-1975. Paris: Quarto Gallimard, 2001, p. 1302. 


\title{
II.
}

Que se tome o caso de uma luta política não mais "conformada ao modelo prescrito", e da qual Foucault efetivamente fará parte: o Grupo de Informações sobre as Prisões, criado em 1971 pelo próprio Foucault, por Pierre VidalNaquet e por Jean Marie Domenach, e autodissolvido em dezembro de 1972. "O Grupo de informações sobre as prisões acaba de lançar seu primeiro questionário. Não é um questionário de sociólogos. Trata-se de deixar a palavra àqueles que têm experiência na prisão." 18 Não se trata, pois, de fazer com que os prisioneiros "tomem consciência" de sua situação - "a consciência está lá, perfeitamente clara, sabendo bem quem é o inimigo. Mas o sistema atual the recusa os meios de se formular, de se organizar." ${ }^{19}$ Como situar, então, a ação do GIP? Vejamos o que diz o "Prefácio" à Enquête dans vingt prisions, título da primeira brochura publicada pelo Grupo (maio de 1971):

\begin{abstract}
Assim se situam os questionários-intolerância [enquêtes-intolérance] que nós agora empreendemos. 1) Estes questionários não são destinados a melhorar, a adoçar, a tornar mais suportável um poder opressivo. Eles são destinados a atacá-lo lá onde ele se exerce sob outro nome - aquele da justiça, da técnica, do saber, da objetividade. Cada um deles deve ser um ato político. 2) Eles visam a alvos precisos, instituições que têm um nome e um lugar, gestores, responsáveis, dirigentes - que fazem vítimas, também, e que suscitam revoltas mesmo entre aqueles encarregados dessas funções. Cada um deve ser o primeiro episódio de uma luta. 3) Eles reagrupam, ao redor desses alvos, camadas diversas que a classe dirigente conservou separadas pelo jogo das hierarquias sociais e dos interesses econômicos divergentes. Eles devem derrubar essas barreiras indispensáveis ao poder, reunindo detentos, advogados e magistrados; ou, ainda, médicos, doentes e o pessoal hospitalar. Cada um deve, em cada ponto estratégico importante, constituir um front, e um front de ataque. 4) Estes questionários não são feitos do exterior por um grupo de técnicos: os questionadores, aqui, são os próprios questionados. A eles a tarefa de tomar o encargo da luta que impedirá a opressão de se exercer. ${ }^{20}$
\end{abstract}

Por eleger como alvo as prisões ("Desde Maio de 68, o aparelho judiciário - instrumento relativamente silencioso e dócil até aqui - foi 'superutilizado" ${ }^{21}$ ), por sua luta pontual, por querer dar voz àqueles que não a têm, a experiência do GIP se encontra em consonância com uma démarche (aquela da genealogia) atenta aos "pequenos eventos" que subsistem silenciosamente e que permitem à reflexão realizar o "diagnóstico" atento das erupções de

18 FOUCAULT, Michel. "Sur les prisons”. In: Dits et écrits I. 1954-1975, op. cit., pp. 1043-1044.

19 Idem, ibidem, p. 1044.

20 FOUCAULT, Michel. "Préface à Enquête dans vingt prisons". In: Dits et écrits I. 1954-1975, op. cit., pp. 10631064.

21 Idem, ibidem. 
forças e resistências inéditas no seio da sociedade: se "discursos como estes, por exemplo, o dos detentos ou dos médicos de prisões, são lutas, é porque ao menos por um instante eles confiscam o poder de fala da prisão". ${ }^{22}$ É preciso que este "discurso desqualificado" e essas "revoltas isoladas" se transformem em "saber comum e em prática coordenada"; é preciso, enfim, não acumular conhecimentos sobre as prisões, mas fazer "crescer a nossa intolerância [ao poder] e fazê-la uma intolerância ativa". ${ }^{23}$ "Tornemo-nos intolerantes a propósito das prisões, da justiça, do sistema hospitalar, da prática psiquiátrica, do serviço militar, etc." ${ }^{24} \mathrm{E}$ a genealogia foucaultiana reclamará aquilo que sua arqueologia já reclamara: a impossibilidade de fazer o pensamento repousar - ou originar-se - em um discurso absoluto; a denúncia de uma razão monológica, que em seu movimento arrasta para dentro do sorvo de sua absoluta auto-referência os meios de conscientização e emancipação, transformando-os em outros tantos instrumentos de "objetivação" e controle.

Afinal, não é no abandono do terreno do "saber" que Foucault se volta ao "poder" - cada uma destas instâncias não é estática em relação à outra. Ao contrário, elas são tramadas em uma interdependência que proíbe fazer do poder o "outro do saber"; assim como a problemática ética, bem o sabemos, de modo algum se articulará em Foucault como o "outro do poder". Da perspectiva da economia interna do discurso foucaultiano, portanto, podese afirmar que se tratou de levar até o fim as implicações mais extremas do postulado - de talhe nietzschiano - que corelaciona a "vontade de saber" às "relações de poder". Dito de outro modo: é a própria arqueologia que fornece o ponto de partida foucaultiano para um cruzamento das formas modernas do saber com a dinâmica peculiar da vontade de verdade que as envolve e que, ao fazê-lo, repõe sem cessar o caráter dissimulado das práticas de poder que as sustentam. (E isso de tal modo que somente aos leitores desatentos caberia o espanto, ou a decepção, com a seguinte afirmação de Foucault, pronunciada em 1983: "Não sou de modo algum um teórico do poder"25).

Nesta medida, assinalemos apenas esta ideia-chave, pronunciada por Deleuze em seu diálogo com Foucault em 1972: "você foi o primeiro a nos ensinar algo de fundamental, ao mesmo tempo em seus livros e no domínio da prática: a indignidade de falar pelos outros." 26 "A indignidade de falar pelos outros" - aqui se trama o princípio do tipo de intervenção política requerida

22 FOUCAULT, Michel. "Les intellectuels et le pouvoir". In: Dits et écrits I. 1954-1975, op. cit., p. 1181.

23 FOUCAULT, "Sur les prisons", op. cit., p. 1044.

24 Idem, ibidem.

25 FOUCAULT, Michel. "Structuralisme et poststructuralisme". In: Dits et écrits II. 1976-1988, op. cit., p. 1270.

26 FOUCAULT, "Les intellectuels et le pouvoir”, op. cit., p. 1177. 
do intelectual pelo pensamento foucaultiano: não se trata mais de "colocar-se 'um pouco à frente ou um pouco ao lado' para dizer a muda verdade de todos", mas sim

/.../ de lutar contra as formas de poder exatamente onde ele é, ao mesmo tempo, o objeto e o instrumento: na ordem do saber, da "verdade", da "consciência", do “discurso". É por isso que a teoria não expressará, não traduzirá, não aplicará uma prática; ela é uma prática. Mas local, regional /.../, não totalizadora. Luta contra o poder, luta para fazê-lo aparecer e feri-lo onde ele é mais invisível e mais insidioso. ${ }^{27}$

Se o "poder político não está ausente do saber" - é a urdidura entre o exercício do poder e a manifestação da verdade que constitui a relação de forças de nossa sociedade -, e se, de outra parte, "é o movimento para se desembaraçar do poder que deve servir de revelador das transformações do sujeito e das relações que ele estabelece com a verdade"28, então o dilema do intelectual não será tanto aquele de uma consciência dilacerada entre o universal e o particular (para retomar uma expressão sartriana ${ }^{29}$ ), mas sim aquele de "possuir o saber do poder" e "denunciar o poder do saber" intelectual deve falar a partir do lugar que ocupa, e não em lugar dos outros, e isso sob pena de repor em circulação a mesma "política de verdade" que a ele caberia denunciar. ${ }^{31}$ Mas se assim o é, então tratar-se-á, como vimos acima, de uma luta local, regional - uma luta que consiste em tornar visíveis os mecanismos dissimulados do poder, e que, ao fazê-lo, venha a reconhecer que "aquilo que faz a generalidade da luta é o próprio sistema do poder, em todas

27 Idem, ibidem, p. 1176.

28 FOUCAULT, Du gouvernement des vivants, op. cit., aula do dia 30 de janeiro de 1980, referência C62 (4.1).

29 “/.../ il y a des techniciens du savoir pratique qui s'accommodent fort bien de leur contradiction ou qui se débrouillent pour éviter d'en souffrir. Mais quand l'un d'eux se rend compte qu'il travaille l'universel pour servir le particulier, alors la conscience de cette contradiction - ce que Hegel appelait conscience malheureuse - est précisément ce qui le caractérise comme intelectuel." C.f. SARTRE, Jean-Paul; PINGAUD, Bernard; MASCOLO, Dionys. Du rôle de l'intellectuel dans le mouvement révolutionnaire. Le Désordre, collection publiée sous la responsabilité de Jean Schuster. Paris: L'Astrolabe, 1971, p. 11.

30 Tomamos de empréstimo, para uso pessoal, um dos subitens de um artigo publicado recentemente (2006) por Francis Wolff. Em seu artigo, Wolff traça um horizonte geral dos dilemas dos intelectuais a partir de duas matrizes basilares: 1) a matriz socrática; 2) a matriz sofística. No entanto, em Wolff a rubrica "Segundo dilema: ter o saber do poder ou denunciar o poder do saber?" servirá para a demarcação da oposição Jean-Paul Sartre versus Pierre Bourdieu. A oposição Sartre versus Foucault, por sua vez, terá lugar em um outro subitem - "Primeiro dilema: intelectual específico ou intelectual total?". Para nós, nos limites de uma breve apresentação como esta, é o dilema entre "ter o saber do poder ou denunciar o poder do saber" que levará Foucault a opor ao "intelectual total" de tipo sartriano o "intelectual específico". Cf. WOLFF, Francis. "O dilema dos intelectuais." Trad. Paulo Neves. In: NOVAES, Adauto (Org.). O silêncio dos intelectuais, op. cit., pp. 45-68.

31 “Je considère que le rôle de l'intellectuel aujourd'hui n'est pas de faire la loi, de proposer des solutions, de prophétiser, car, dans cette fonction, il ne peut que contribuer au fonctionnement d'une situation de pouvoir déterminée qui doit, à mon avis, être critiquée." Cf. FOUCAULT, "Entretien avec Michel Foucault". In: Dits et écrits II. 1976-1988, op. cit., p. 905. 
as suas formas de exercício e aplicação". ${ }^{32}$ Neste sentido, diz-nos Foucault, é possível que "as lutas que se realizam agora e as teorias locais, regionais, descontínuas, que estão se elaborando nessas lutas e fazem parte delas, sejam o começo de uma descoberta do modo como se exerce o poder". ${ }^{33}$

Fazendo de si mesmo o protótipo deste tipo intelectual requerido por sua arqueo-genealogia, Foucault faz mais do que simplesmente reencetar a sua vocação - presente desde História da loucura - para reenviar a análise discursiva às práticas sociais e institucionais de sua realização: ele refina seus instrumentos conceituais, repensa seu próprio itinerário em vista das formas de intervenção política nas quais se engaja, remaneja sua teorização em função da compreensão da "teoria filosófica" como "uma prática subjetiva cuja vocação é a luta contra o poder". ${ }^{34}$ Como dissemos acima, é o aprendizado da "luta pontual": o poder trabalha o corpo, penetra no comportamento, entrecruza-se fisicamente com ele, e é nesse trabalho que devemos surpreendê-lo, é aqui que é preciso agir.

\section{III.}

Destarte, aquela que é talvez a tese mais surpreendente da genealogia foucaultiana - o indivíduo como produção do saber e do poder - "ganha as ruas", por assim dizer, em uma prática intelectual - pequena démarche lateral de "mise en question" da necessidade de todo o poder, isto é, de sua aceitação de pleno direito - na qual a "teoria", agora tornada "prática", perde suas prerrogativas de "atividade totalizadora", volta-se contra seu agente e produz a denúncia de que também o intelectual, na medida em que se apresenta como um agente da "consciência" ou do "discurso", faz parte deste "sistema de poder que barra, proíbe, invalida" discursos e saberes não qualificados. ${ }^{35}$ Note-se bem, e sublinhe-se: é a tese mais surpreendente da genealogia foucaultiana que "ganha as ruas" - ao requerer um tipo intelectual cuja voz não é mais portadora de "valores universais", um tipo que não é mais "representativo" ou "representante", que não é mais "sujeito"36, ao substituir, enfim, o intelectual universal pelo intelectual específico, é o desmascaramento da realidade das

32 FOUCAULT, “Les intellectuels et le pouvoir”, op. cit., p. 1183.

33 Idem, ibidem, p. 1182.

34 LE BLANC, Guillaume; TERREL, Jean. "Foucault au Collège de France: un itinéraire". In: LE BLANC, Guillaume; TERREL, Jean (Dir.). Foucault au Collège de France: un itinéraire. Histoire des Pensées. Bordeaux: Presses Universitaires de Bordeaux, 2003, p. 12.

35 FOUCAULT, "Les intellectuels et le pouvoir", op. cit., p. 1176.

36 Idem, ibidem, p. 1175. 
relações entre e verdade e poder que está em jogo; logo, a função do intelectual será a de agir sobre a "produção da verdade" na medida em que a verdade, ela própria considerada na perspectiva de eixo gravitacional das relações de saber/poder, for implicada em seu aspecto de "assujeitamento".

Assim sendo, a verdade não é sem efeito, ela é produtora de regimes de identidade que são, ao mesmo tempo, princípios de exclusão:

Há um combate "pela verdade" ou, ao menos, "em torno da verdade" - entendendose, ainda uma vez, que por verdade não quero dizer o conjunto das coisas verdadeiras a descobrir ou fazer aceitar, mas o conjunto das regras segundo as quais distinguese o verdadeiro do falso e atribui-se ao verdadeiro efeitos específicos de poder; entendendo-se também que não se trata de um combate em favor da verdade, mas em torno do estatuto da verdade e do papel econômico-político que ela desempenha. ${ }^{37}$

O registro da investigação genealógica é aquele de uma luta, um embate; em todo caso, a mais importante das lutas - porque despida de pretensões identitárias - diante de um contexto político-filosófico que embaralha as evidências, desagrega as linhas da razão, expõe-na em suas fragilidades, naquilo que a denuncia - lembremos aqui de um belo texto de François Ewald - como uma "vontade de saber ultrapassada". ${ }^{38}$ Trata-se, em uma palavra, de "ser respeitoso quando uma singularidade se insurge, intransigente quando o poder infringe o universal". ${ }^{39}$ Intransigência que encontrará no "último Foucault", e a propósito das "práticas" ou "técnicas" de existência, de um "exercício de si no pensamento", todo um terreno de questões éticas fundamentais de resistência e produção de si no âmbito da transgressão manifesta da universalidade; transgressão dos efeitos prescritivos do poder. Como dirá Foucault na Introdução de $O$ uso dos prazeres, segundo volume de sua História da sexualidade, "Há sempre algo de irrisório no discurso filosófico quando ele quer, do exterior, fazer a lei para os outros, dizer-lhes onde está a sua verdade, e como encontrá-la". ${ }^{40}$

37 FOUCAULT, Michel. "Intervista a Michel Foucault". In: Dits et écrits II. 1976-1988, op. cit, p. 159.

38 EWALD, François. "O fim de um mundo". In: ESCOBAR, Carlos Henrique de (Org.). Michel Foucault (19261984): o dossier, últimas entrevistas. Trad. Ana Maria de A. Lima, Maria da Glória R. da Silva (O retorno da moral). Rio de Janeiro: Taurus Editora, 1984, p. 99.

39 FOUCAULT, Michel. "Inutile de se soulever?" In: Dits et écrits II. 1976-1988, op. cit., p. 794.

40 FOUCAULT, Michel. L'usage des plaisirs. In: Histoire de la Sexualité, v. 2. Bibliothèque des Histoires. Paris: Gallimard, 1984, p. 15. 


\section{Referências bibliográficas}

EWALD, François. "O fim de um mundo". In: ESCOBAR, Carlos Henrique de (Org.). Michel Foucault (1926-1984): o dossier, últimas entrevistas. Trad. Ana Maria de A. Lima, Maria da Glória R. da Silva (O retorno da moral). Rio de Janeiro: Taurus Editora, 1984.

FOUCAULT, Michel. Du gouvernement des vivants: cours au collège de France, du 9 janvier au 26 mars 1980. Inédito. Disponível para consulta em áudio, sob notação: FCL - C 62 (1.1) / C62 (1.2) até FCL - C 62 (12.1) / C62 (12.2), arquivos do Institut Mémoire de L'Édition Contemporaine (IMEC), Caen, aula do dia 30 de janeiro de 1980, referência C62 (4.1).

. A verdade e as formas jurídicas. Trad. Roberto Cabral de Melo

Machado e Eduardo Jardins Morais. Supervisão final do texto Lea Porto de Abreu Novaes et al. Rio de Janeiro: Editora NAU, 2003.

Gallimard, 2001.

. "Préface". In: Dits et écrits II. 1976-1988. Paris: Quarto

. "Le monde est un grand asile". In: Dits et écrits I. 1954-1975.

Paris: Quarto Gallimard, 2001.

. "Toujours les prisons". In: Dits et écrits II. 1976-1988. Paris:

Quarto Gallimard, 2001.

. "Sur les prisons". In: Dits et écrits I. 1954-1975. Paris: Quarto

Gallimard, 2001.

. "Préface à Enquête dans vingt prisons". In: Dits et écrits I.

1954-1975. Paris: Quarto Gallimard, 2001.

. "Structuralisme et poststructuralisme". In: Dits et écrits II. 1976-1988. Paris: Quarto Gallimard, 2001.

. "Les intellectuels et le pouvoir". In: Dits et écrits I. 1954-1975.

Paris: Quarto Gallimard, 2001.

. "Entretien avec Michel Foucault". In: Dits et écrits II. 1976-

1988. Paris: Quarto Gallimard, 2001.

"Intervista a Michel Foucault". In: Dits et écrits II. 1976-1988.

Paris: Quarto Gallimard, 2001.

."Inutile de se soulever?" In: Dits et écrits II. 1976-1988. Paris:

Quarto Gallimard, 2001.

. L'usage des plaisirs. In: Histoire de la Sexualité, v. 2. Bibliothèque des Histoires. Paris: Gallimard, 1984.

FRANÇOIS, Jean. "Aveu, vérité, justice et subjectivité. Autour d'un enseignement de Michel Foucault”. In: Revue Interdisciplinaire d'Études Juridiques, n. 7, 1981. Disponível para consulta em texto datilografado, sob a notação: Compte rendu $d u$ cours "Mal faire, dire vrai. Fonctions de l'aveu" (Louvain, 1981), D 202, arquivos do Institut Mémoire de L'Édition Contemporaine (IMEC), Caen.

LE BLANC, Guillaume; TERREL, Jean (Dir.). Foucault au Collège de France: un itinéraire. Histoire des Pensées. Bordeaux: Presses Universitaires de Bordeaux, 2003. 
SARTRE, Jean-Paul. Critique de la raison dialectique (précédé de Question de méthode). Tome I: théorie des ensembles pratiques. Bibliothèque des Idées. Paris: Gallimard, 1960.

; PINGAUD, Bernard; MASCOLO, Dionys. Du rôle de l'intellectuel dans le mouvement révolutionnaire. Le Désordre, collection publiée sous la responsabilité de Jean Schuster. Paris: L'Astrolabe, 1971.

WOLFF, Francis. "O dilema dos intelectuais." Trad. Paulo Neves. In: NOVAES, Adauto (Org.). O silêncio dos intelectuais. São Paulo: Cia da Letras, 2006. 